Publisher homepage: www.universepg.com, ISSN: 2663-6913 (Online) \& 2663-6905 (Print)

https://doi.org/10.34104/ajpab.020.01290138

American Journal of Pure and Applied Biosciences

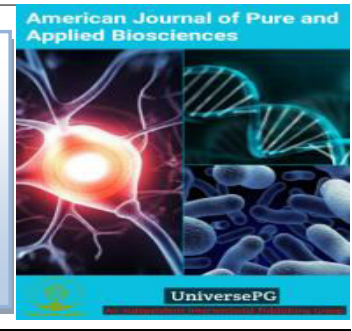

\title{
Drying Effect on Mechanical Properties of Bio-nanocomposite Films Fabricated from Self-assembledCellulose Nanocrystals into Potato Starch
}

\author{
Mohammad Mamunur Rashid ${ }^{1}$, Jahidul Islam Sharif ${ }^{1}$ and Md. Ashaduzzaman ${ }^{1,2 *}$ \\ ${ }^{1}$ Department of Applied Chemistry and Chemical Engineering, University of Dhaka, Dhaka 1000, Bangladesh; and \\ ${ }^{2}$ Treasurer, Comilla University, Comilla 3506, Bangladesh. \\ *Corresponding author: azaman01@du.ac.bd
}

\begin{abstract}
Composite films with higher mechanical properties from naturally occurring degradable materials are of present demand to achieve goals of sustainable development. Interaction within composite constituents during drying controls mechanical properties. Here, bio-nanocomposite films were first prepared from cellulose nanocrystals synthesized from jute fibres and extracted potato starch with the same chemical formulations. The filler, nanocrystals consist of nanorod-like cellulose particles obtained as an aqueous suspension by sulfuric acid $\left(\mathrm{H}_{2} \mathrm{SO}_{4}\right)$ hydrolysis of jute fibres and the matrix was prepared by plasticization of potato starch after disruption of starch granules with water and glycerin. Nanocomposite films were obtained by casting the homogeneous aqueous suspension at $95^{\circ} \mathrm{C}$ and followed by natural drying (atmospheric drying, $25^{\circ} \mathrm{C}$ ) and oven drying at $40^{\circ} \mathrm{C}$. The thickness of the bio-nanocomposites film about $250 \mu \mathrm{m}$ was controlled by using a $2 \mathrm{~mm}$ thick structural glass frame. It is revealed that with increasing the percentage of cellulose nanocrystals in composite films, mechanical properties corresponding to tensile strength and Young's modulus was increased significantly. The film containing the highest quantity of cellulose nanocrystals ( $20 \% \mathrm{w} / \mathrm{w}$ of starch) revealed better properties in case of natural drying (tensile strength $84.2 \mathrm{MPa}$, Young's modulus $0.563 \mathrm{GPa}$, elongation at break 27\%) than the film properties (tensile strength 35.2 MPa, Young's modulus $0.423 \mathrm{GPa}$, elongation at break $20 \%$ ) of oven drying.
\end{abstract}

Keywords: Bio-nanocomposites films, cellulose nanocrystals, starch, self-assembly, potato starch, and drying.

\section{INTRODUCTION:}

Development and engineering of bio-based products and innovative processing technologies which offer sustainability and mitigation of the dependence on fossil fuel are essential for sustainable civilization. Among biopolymers, starch is the most promising renewable bioresource due to its versatility, competetiveness in price, and applicability to various Industries (Yang et al., 2007; Tianyu et al., 2020; Pandey et al., 2020; John and Thomas, 2008). Through destruct- urization by the introduction of mechanical and heat energy or by incorporation of a plasticizing agent (e.g., water, amide, and/or polyols), starch can be processed into thermoplastic materials. Currently, biodegradable plastics are primarily used in food packaging films, shopping bags, and flushable sanitary product backing material (Bertoft, 2017; Rhim, 2007; Beytullah and Fatih, 2012). The use of starch-based materials is greatly hindered by its intractable nature, brittleness, water-sensitivity, and poor mechanical 
strength (Alexander et al., 2013; Kumar et al., 2008; Liu et al., 2009). It has been found that using reinforcing materials in a starch matrix is an effective method to obtain high-performance starch-based biocomposites (Cao et al., 2008). Various types of cellulose fillers such as jute fibers, eucalyptus pulp fibers, flax fiber, tunicin, and ramie fibers, have been prepared and used as reinforcing agents in biocomposites (Chakraborty et al., 2008; John et al., 2007). Natural cellulosic nanocrystals with high aspect ratio have been gaining considerable interest because of their unique and attractive features in terms of functionality, cost effectiveness, and light weight.

Nevertheless, physical properties of various cellulose nanocrystals are significantly identical depending to their distinguished structural compactness, sizes, crystal alignment and overall morphologies. Processing and chemical treatment for fiber extraction involves removing of adhered surface wax, foreign non-cellulosic substances, and chemically broken cellulosic compounds due to the action of harsh chemical. Cellulosic fibers from different sources like cornstalks, rice, and wheat straw are composed of single cells and are about $0.5-3.0 \mathrm{~mm}$ in length, whereas flax fiber is as long as $77 \mathrm{~mm}$ reported by different research groups(Reddy and Yang, 2006; Reddy and Yang, 2007). Besides, cellulosic nanocrystals have a size of $2-50 \mathrm{~nm}$ in one dimension (Dufresne, 2008; Kennedy et al., 2007). However, due to the interactive behavior of cellulose nanocrystals, it is difficult to control uniform dispersion in a matrix or into a solution because aggregation and agglomeration occurs within the nano-phases to form larger structures.

The cellulosic crystal structure, morphology, and crystallinity are mainly varied depending on the crystal sources its processing parameters e.g. pretreatments chemicals, intensity of temperatures, types of solvents, suspension or dry state, and other related conditions. Like in Bangladesh, jute is a renewable and easily growing natural bioresource abundant in many parts of the world. It has several advantages including small environment load, rapid growth, renewability, relatively high strength, and good flexibility. Cellulosic nanocrystals from jute fiber may play an important role in forming new organic

UniversePG I www.universepg.com structural nanocomposites, and is recognized as an attractive candidate for reinforcing agent. However, research in manufacture and use of cellulose nanocrystals from jute is not still up to the mark. Understanding of the structural feature and morphology of jute cellulosic crystals could lead to more and efficient utilization of this bioresource (Wei-ming et $a l ., 2009)$. In this study, hydrolysis was carried out to synthesize nanocrystals from jute fibers digestion using $64 \% \mathrm{w} / \mathrm{v}$ sulfuric acid at $60{ }^{\circ} \mathrm{C}$. The objective of the study was set to investigate the drying effect on mechanical properties of the cellulose nanocrystals assisted potato starch bio-nanocomposite films. The results of the research work would play vital role to direct the right pathway for the fabrication of environment friendly films for food packaging.

\section{MATERIALS AND METHODS:}

\section{Materials}

Jute, potato and bleaching powder $\left(\mathrm{CaOCl}_{2}\right)$ were collected from local market (Dhaka, Bangladesh). Sulfuric acid $\left(98 \%, \mathrm{H}_{2} \mathrm{SO}_{4}\right)$ and glycerin were purchased from Sigma-Aldrich, and were used as received. Pre-designed glass frame was used to control the size and shape of the films.

\section{Methods}

Preparation of Cellulose Nanocrystals - At first 64\% w/v sulfuric acid was prepared (Revol et al., 1994; Carla and Ticiane, 2019). For this $35 \mathrm{~mL}$ of sulfuric acid (98\%, specific gravity 1.85) was added slowly into $65 \mathrm{~mL}$ of distilled water in a $250 \mathrm{~mL}$ beaker to prepare $100 \mathrm{~mL}$ of aqueous acid solution. Later 2.765 $\mathrm{g}$ of cellulose (jute fibres) was then immersed into acid solution for hydrolysis. This solution was then mechanically stirred at $60^{\circ} \mathrm{C}$ for 35 minutes. The aqueous black suspension was subsequently diluted with an equal part of water (cold) and washed by successive centrifugation at $10,000 \mathrm{rpm}$ and at $25^{\circ} \mathrm{C}$ (three times) (Fig 1). Dialysis against distilled water was performed to remove free acid in dispersion. After this we obtained the grey like substance which was subjected to bleach.

Bleaching - An amount of $40 \mathrm{~g}$ bleaching powder was dissolved in $400 \mathrm{~mL}$ water to make a bleaching solution. The solution prepared from commercially 
available bleaching powder was mechanically stirred at $40^{\circ} \mathrm{C}$ for 25 minutes and removed undissolved impurities by decantation. The collected bleaching solution of about $100 \mathrm{~mL}$ was first added to the hydrolyzed cellulose suspension, which was mechanically stirred for 30 minutes at $40^{\circ} \mathrm{C}$. After 10 minutes of stirring the suspension was kept in rest without disturbance, clear brownish solution was decanted again. Similarly, decolorization treatment with the bleaching solution was carried out three times. Finally, a white suspended jelly like material was washed by cold water several times to remove free bleaching agents from cellulose nanocrystals. The nanocrystals were then recovered by drying from an atmospheric dryer at $105^{\circ} \mathrm{C}$.
Extraction of starch from potato - Extraction of starch from potato was carried out according to the procedure as described. At first about $100 \mathrm{~g}$ cleaned potato but without peeling was grated and charged into a blending machine with addition of about $100 \mathrm{~mL}$ distilled water. After 10 minutes blending, the mass of potato was carefully transferred and diluted with more $100 \mathrm{~mL}$ water to settle into the beaker. Mass of residual potato from the beaker, leaving behind the white starch (settled at the bottom) was separated. The mass of the beaker was washed several times with copious water and filtered using a cloth to collect granular starch (Fig 2).

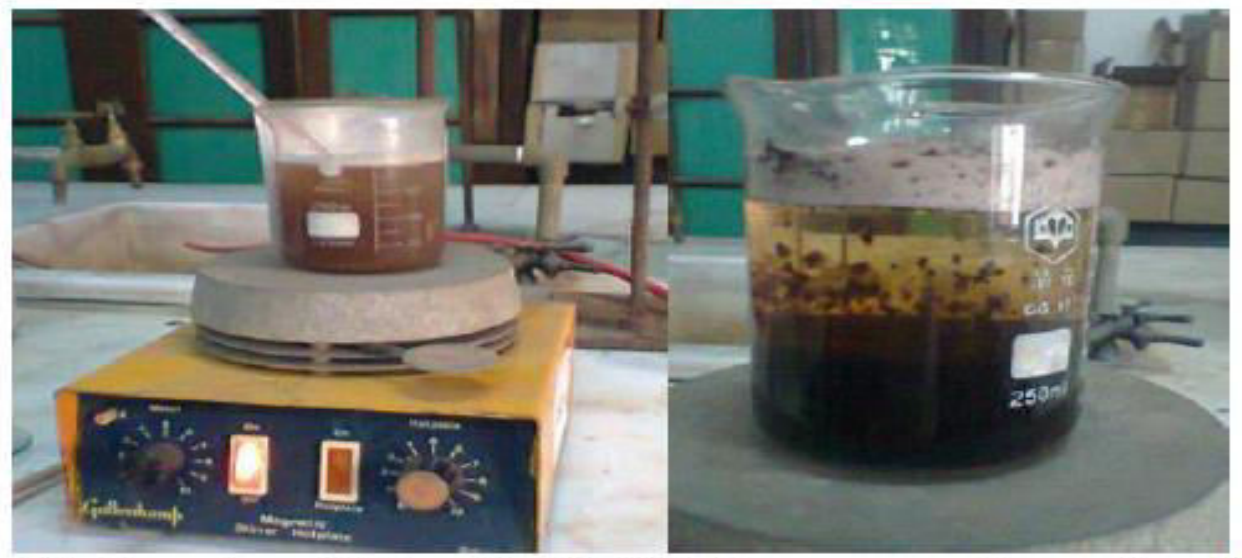

Fig 1: Hydrolysis of jute using $64 \% \mathrm{w} / \mathrm{v} \mathrm{H}_{2} \mathrm{SO}_{4}$ for preparation of cellulose nanocrystals (left: initial stage, right: after hydrolysis).
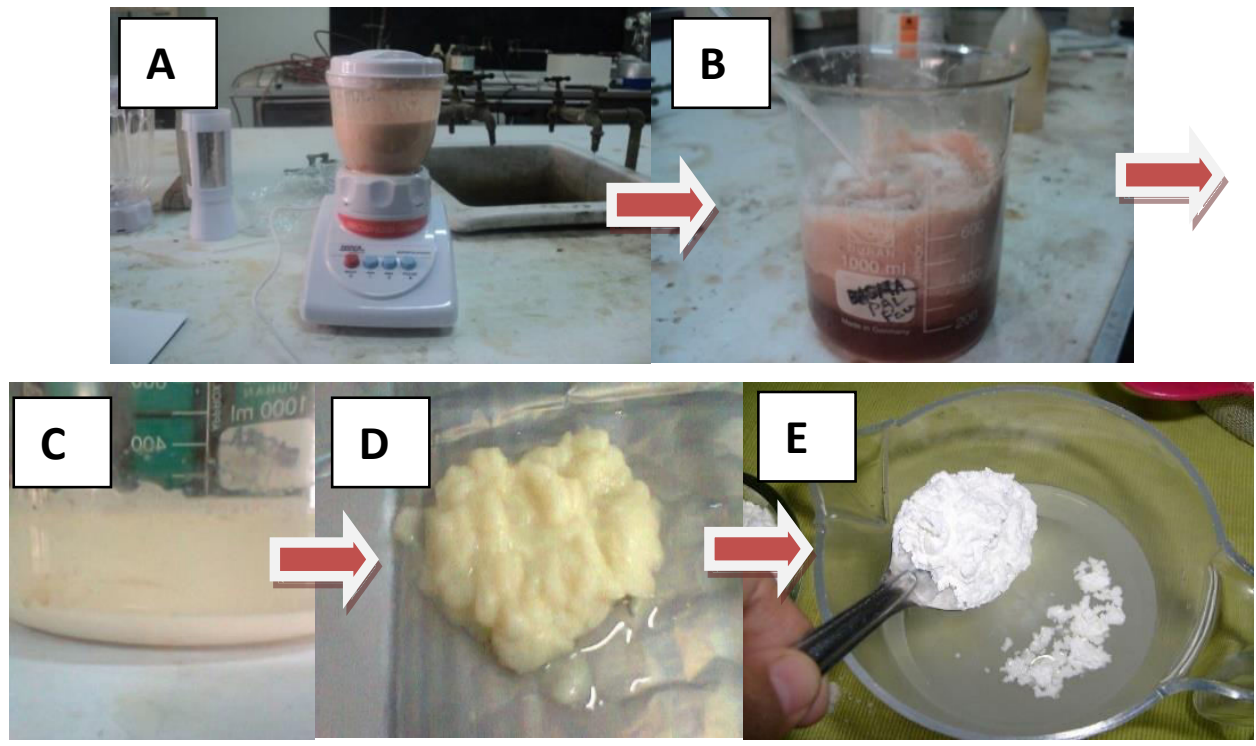

Fig 2: Extraction of starch from potato (A) potato chopped was blended, (B) settling, (C) washing, (D) screening, and (E) dried starch powder. 
Neat Film Preparation - A quantity (3 g of mixture) of dried starch and glycerol (2:1) was first dispersed into $35 \mathrm{~mL}$ of distilled water. Then the mixture was subjected to heat at $95{ }^{\circ} \mathrm{C}$ for 15 minutes with mechanical stirring. Gelatinized starch was cast and stored in a non-ventilated oven at $40{ }^{\circ} \mathrm{C}$ for $24 \mathrm{~h}$.

Composites Film Preparation - Starch (2 g) was first dispersed in distilled water $(35 \mathrm{~mL})$. Besides, cellulose nanocrystals $(5 \%, 10 \%, 15 \%$ and $20 \% \mathrm{w} / \mathrm{w}$ of starch) were homogeneously dispersed in $1 \mathrm{~g}$ of glycerol, so that the agglomeration was prevented by sonication for 10 minutes. Then the two mixtures were added together and stirred mechanically while the solution was heated at $95^{\circ} \mathrm{C}$ for 15 minutes. The mixture was then stirred and sonicated for $10 \mathrm{~min}$ to remove microbubbles before casting onto the surface of glass wrapped with Teflon sheet. The film was dried by atmospheric evaporation or in an oven at $40^{\circ} \mathrm{C}$ for 24 h.

Tensile properties - Tensile strength, elongation at break and Young's modulus of the films with dimensions of $7 \times 4 \times 0.25 \mathrm{~mm}$ (length $\times$ width $\times$ thickness), conditioned at $75 \% \mathrm{RH}$, were measured using a universal testing machine (CMT6503, Shenzhen SANS Test Machine Co. Ltd., Shenzhen,
China). Initial gap of the jaw was fixed at $10 \mathrm{~mm}$. Dried films with an average thickness of around 250 $\mu \mathrm{m}$ were obtained by measuring with Phynix digital micrometer.

\section{RESULTS AND DISCUSSION:}

Cellulose nanocrystals with some microfibrils from jute were prepared by hydrolysis in presence of $64 \%$ $\mathrm{H}_{2} \mathrm{SO}_{4}$ at $60{ }^{\circ} \mathrm{C}$. The product obtained from reactor was deep brown due to presence of some unknown coloring entities in the processed jute and may be some undesirable reaction with oxygen occurred in the reactor. Aqueous solution $(10 \% \mathrm{w} / \mathrm{v})$ of commercial bleaching powder was used to purify the nanocrystals. It was noteworthy to mention that the purification was not complete after bleaching at room temperature (25 ${ }^{\circ} \mathrm{C}$ ) and then the product still contained little brown color. Whereas, when bleaching was carried out at 50 ${ }^{\circ} \mathrm{C}$, all of the coloring materials were removed leaving a white cellulose nanocrystals as shown in the Fig 3A. Besides, the yield of extracted starch from potato was about $18 \%$. The higher yield of starch and low cost of potato indicate that it can be a potential source of industrial raw material as shown in Fig 3B. A white cotton fabric (cloth) was used for separation of starch by filtration.

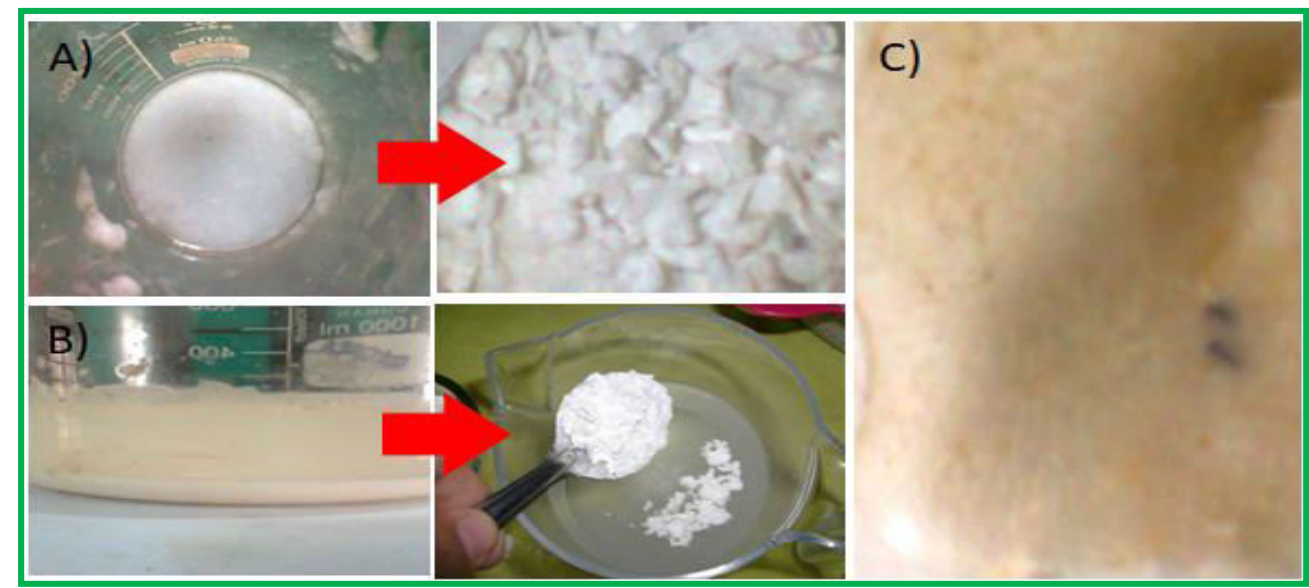

Fig 3: Shows the optical images of (A) cellulose nanocrystal, (B) potato starch, and (C) bionanocomposite film.

Therefore, a portion of starch was trapped into the blended potato mass. The yield of starch may be increased by using an improved sieving technique. Biopolymers are usually hydrophilic and thus, water is the solvent used most often to dissolve to obtain film forming solutions. Instead of water some other solvents with or without water can be used to dissolve biopolymers. Usually, heating with solvent is needed to disrupt the native structure of the biopolymer to obtain a film forming solution. Plasticizer is added to the film forming solution at a convenient stage of the process to obtain flexible and elastic films which are 
often desired. There are various biomaterial film forming processes such as casting, spraying, extrusion and thermo-molding. The most common process to produce films on a laboratory scale is casting, which was used to produce films for testing. In this process, a film forming solution was cast on a non-adhesive surface of glass covered with Teflon ribbon. Water or solvent is evaporated from the solution in order to form the film. As a result of solvent evaporation, biopolymer was left onto the Teflon surface and the basic film structure was developed by hydrogen bonding as shown in Fig 3C. Environmental parameters, such as temperature and a irrelative humidity, during the evaporation stage could be used to control some of the film properties.

SEM of Cellulose nanocrystals - Scanning electron microscopy (SEM) observation was performed using Philips CM200 microscope (Eindhoven, The Netherlands) with a $20 \mathrm{KV}$ accelerating voltage. A drop of a dilute cellulose nanocrystals sand starch suspensions were deposited on a glow disc-graded carbon-coated microscopy grid. After one minute, the liquid in excess was blotted with filter paper and the remaining film was allowed to dry. Because of atmospheric drying, an agglomeration of crystals was observed from SEM images. Since we have followed an established procedure to synthesize nanocrystals from jute, the synthesized nanocrystals having a 100-150 $\mathrm{nm}$ and $5-10 \mathrm{~nm}$ diameter were maintained which is available in literature (Carla and Ticiane, 2019). Fig 4A, and $\mathbf{B}$ shows the SEM images of cellulose nanocrystals processed in $64 \% \mathrm{w} / \mathrm{v}_{2} \mathrm{SO}_{4}$ and starch extracted from local potato.

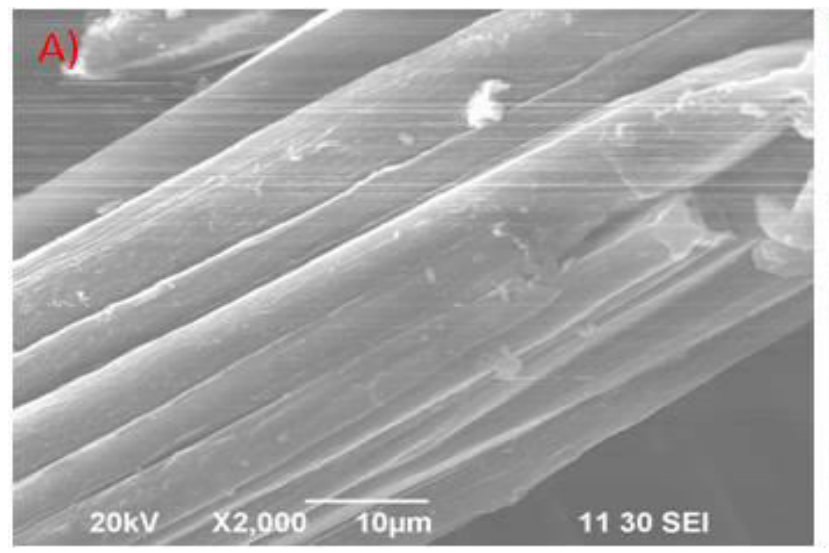

Grain size of potato starch was also checked by SEM and a range of 10-40 $\mu \mathrm{m}$ was found (Fig 4) which is also complied by literature survey (Daniel et al., 2019), particle shapes of the potatoes starch were mainly spherical and polyhedral. This is in conformity with common starch.

Mechanical properties - Humidity is one of the most important factors affecting the mechanical properties of thermoplastic starch. For example, the mechanical strength of starch composites can reach $20 \mathrm{MPa}$ in $0 \% \mathrm{RH}$; however, at high moisture conditions, the tensile strength may be below $1 \mathrm{MPa}$ due to water plasticization (Glenn et al., 2007). Cellulose nanocrystals are reported to have a high modulus, up to 134 $\mathrm{GPa}$, and strong tensile strength of more than $4 \mathrm{GPa}$ (Sakurada et al., 1962).

\section{Determination of Tensile strength and Young's} modulus - It was possible that varying amounts of cellulose nanocrystals might affect the film thickness and consequent the mechanical properties. Film thickness measurement was, therefore, carried out using Phynix digital micrometer. It was found that film thickness of films containing 5, 10, 15 and 20 wt $\%$ cellulose nanocrystals around $250 \mu \mathrm{m}$. These results indicated that the dry film thickness was not significantly varied with different amounts of added nanocrystals. The resulting mechanical properties of film therefore were reasonably comparable. The results show that the preparation of starch-based composite with cellulose nanocrystals could improve the mechanical properties. The addition of cellulose nanocrystals increases the composite film strength and stiffness.

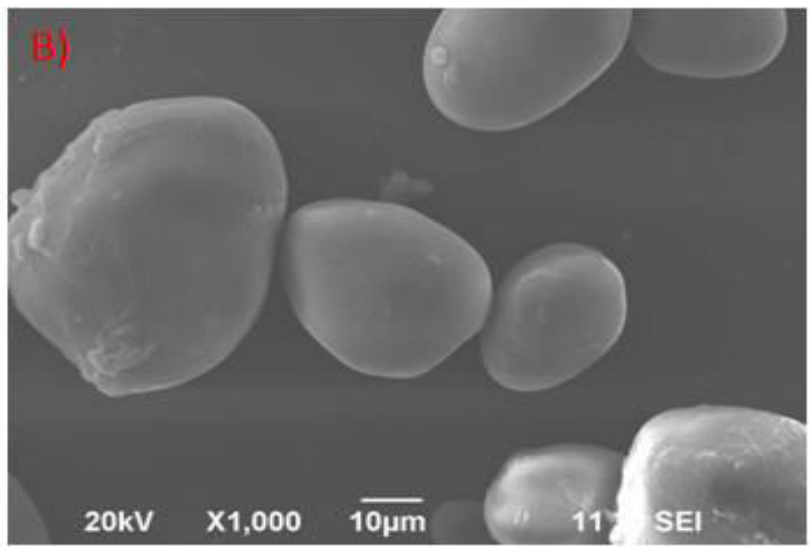

Fig 4: Shows the SEM images of (A) cellulose nanocrystals, and (B) potato starch granules. 
Four types of nanocomposite films and a film of starch were prepared to study the effects of nano-crystals of jute fiber attributes and matrix compatibility on several end-use properties. During film preparation of the composite, we have considered some factors so that an identical film could be produced. Therefore, a glass sheet with $2 \mathrm{~mm}$ thick was chosen and cut in a rectangular shape. This glass sheet was used to produce a rectangular pan using another glass boundary and the mixture of mass was poured in the void and open space of rectangular pan. The bubble of the suspension was removed by 10 minutes sonication. Then the film was dried in atmosphere as well as in an atmospheric dryer at $40^{\circ} \mathrm{C}$ separately. An increase in the amount of cellulose nanocrystals in the film a gradual increase in both tensile strength and Young's modulus was found. For example, considering the tensile strength values of starch films containing 0,5 , 10,15 , and $20 \mathrm{wt} \%$ cellulose nanocrystals are varies from 58 to $84 \mathrm{MPa}$ for atmospheric drying and 10 to $35 \mathrm{MPa}$ for oven drying films respectively as shown in Fig 5A, and B. Structurally, cellulose nanocrystals are very strong, as a result, the incorporation of nanocrystals into the starch composite filmed to an improvement in both tensile strength and Young's modulus due to the reinforcement effect.

It is revealed from Fig $\mathbf{5 A}$, the film of starch only shows tensile strength about $58 \mathrm{MPa}$, but after 5\% addition of cellulose nanocrystals gives higher tensile strength than the starch film. The increment of strength was remained steady until $15 \%$ of nanocrystals added. With increasing the quantity of cellulose nanocrystals, the tensile strength (MPa) was increased linearly. It is clear that the value of tensile strength of the film containing $15 \%$ of nanocrystals is closer to the tensile strength of the film containing 20 $\%$ of nanocrystals. This phenomenon can be explained as the crystal amount increased excessibly; the binding capacity of matrix was not working significantly. This naturally drying starch film is actually strong due to homogeneous drying. In case of oven drying, the film property, in terms of tensile strength is similar but the values of tensile strength were found below half of natural drying as shown in Fig 5B. Fig 6 shows the comparison of tensile strength between natural drying and oven drying systems.

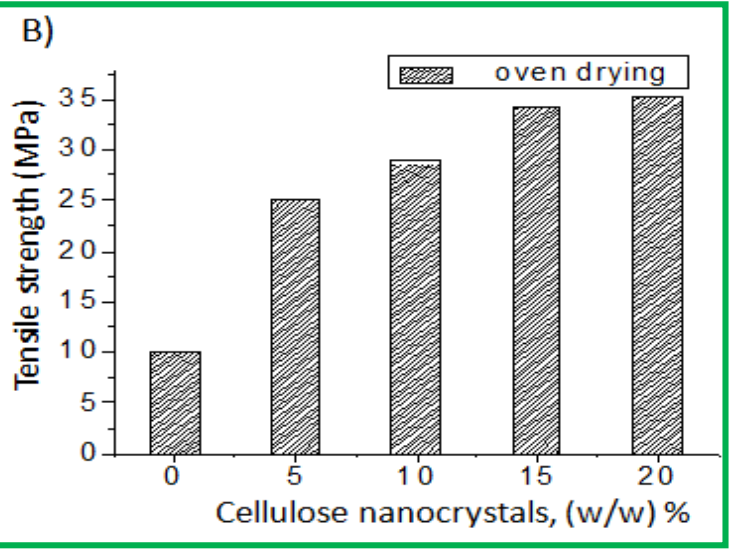

Fig 5: Shows the tensile strength of different composite films at natural drying (A), and oven drying (B).

The overall all strength of composite is stronger for natural drying (filled circle), whereas the oven drying (open circle) produced a hetero system in the film by evaporating the solvents from surface of film rapidly, but a soft interior remain in the film leads to weaken the film property. In 1994, Bader and Göritz (1994) reported that a starch films swelled at high relative vapor pressure (RVP) due to high water content of film. During swelling, number of hydrogen bonds between starch-polyol and starch-starch decreases and number of hydrogen bonds between starch-water and polyol-water increases resulting in weakened structure of the film which do not last remarkable deformations. This was observed at high RVP as elongation of film was found to decrease instead of increase which was expected to occur with increasing plasticizer content 
and RVP as reviewed, e.g., by Krochta, (2002). Moreover, the Young's modulus and tensile strength of glycerol plasticized potato starch films increased with increasing the amount of crystalline cellulose nanocrystals (Fig 6). Crystallization of starch components occurred during film formation increasing
Effect of cellulose nanocrystals on \% Elongation at break - The maximum \% elongation at break was found from the film of starch and glycerol. Here, also the elongation values of the films in case of natural drying showed higher than the values of oven drying.
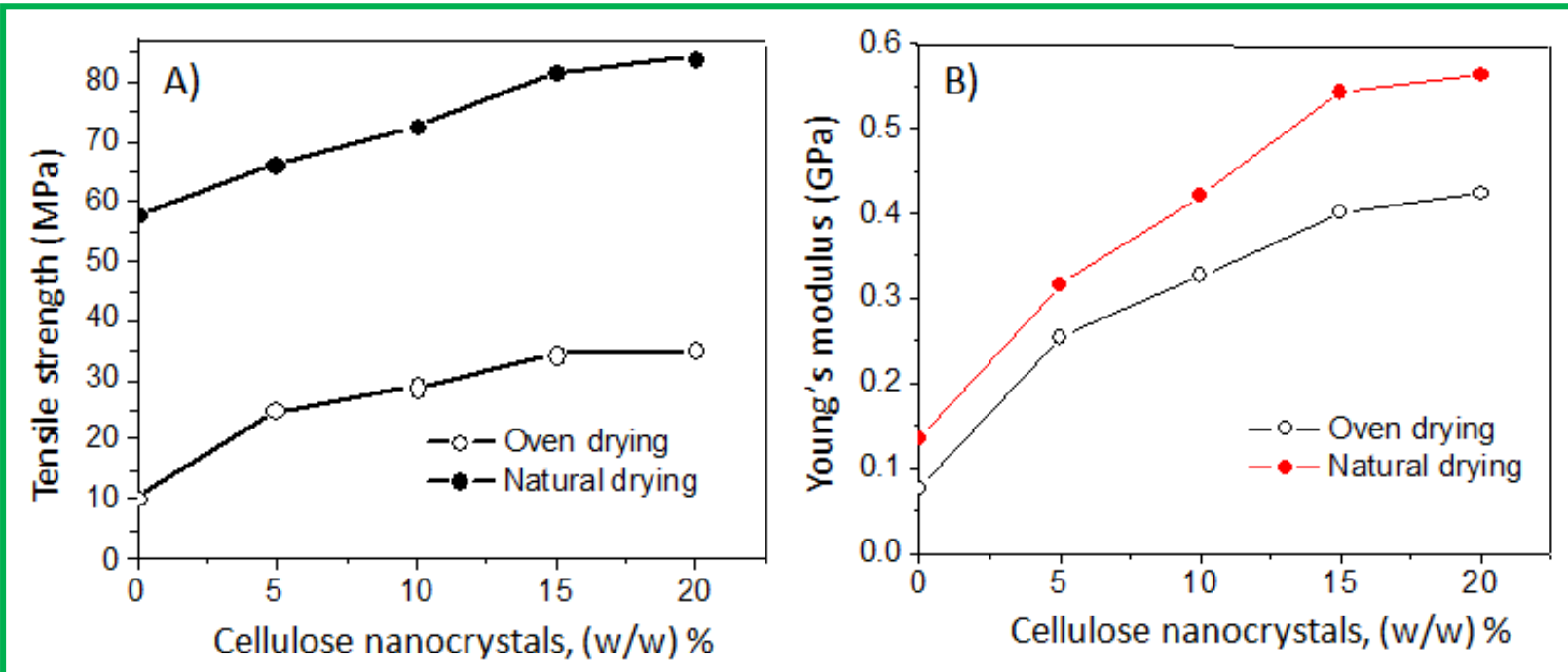

Fig 6: Shows a comparison of natural drying and oven drying of composite film in terms of (A) tensile strength, and (B) Young's modulus.

Young's modulus and tensile strength which could be observed from increased rigidity of the starch film. The Young's modulus and tensile strength of glycerol plasticized cassava starch films have been reported to increase with increasing amount of added amylose due to a denser polymer network (Alves et al., 2007).
The maximum decreasing of the value is observed when $5 \% \mathrm{w} / \mathrm{w}$ of cellulose nanocrystals was added. After sharp decreasing, the elongation at break decreased very slowly. On the other hand, this can be explained as the addition of cellulose nanocrystals proceeded, the expansion of the film was reduced and

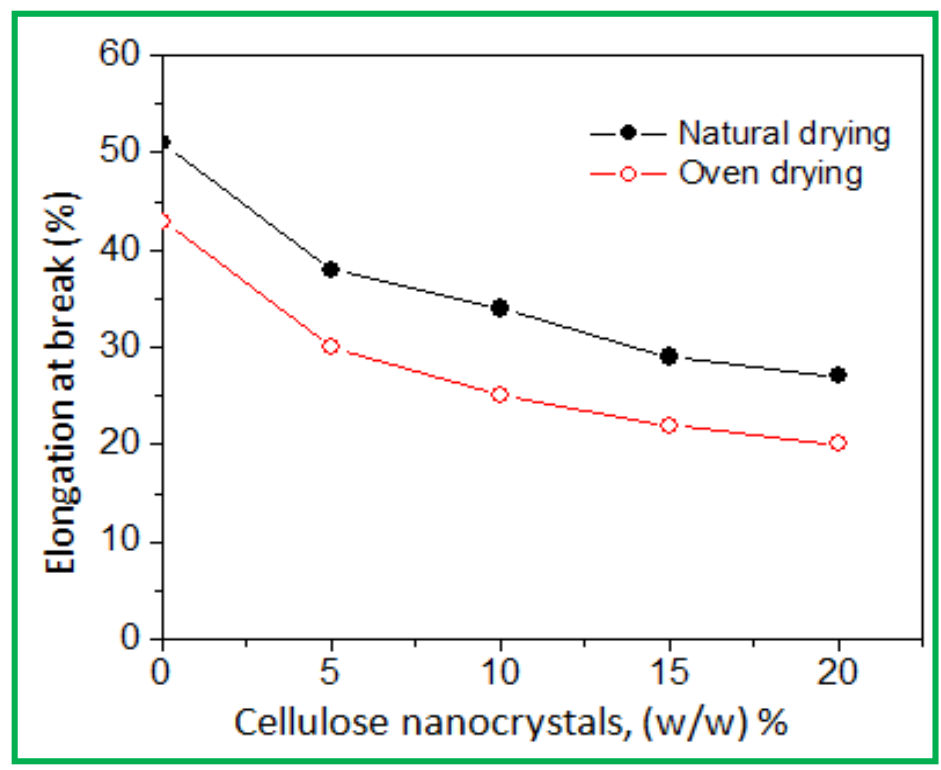

Fig 7: Shows the percentage elongation at break of different composite films prepared at natural drying and oven drying. 
rigidity as well as toughness was increased as shown in Fig 7. In 1999, Biliaderis et al. (1999) reported that elongation of starch films increased remarkably as water content increased because of change from glassy to rubbery state, which supports the result oppositely. In the schematic Fig $\mathbf{8 A}$, it is revealed that the surface of film was dried and became brittle when the film was rapidly dried by oven drying. As a result, the core matrix of the film remained soft and wet which produce mechanically a weak film due to lack of interactive compactness. Besides, natural drying leads to produce a homogeneously dehydrated film which makes relatively compacted and mechanically stronger films as shown in Fig 8B.

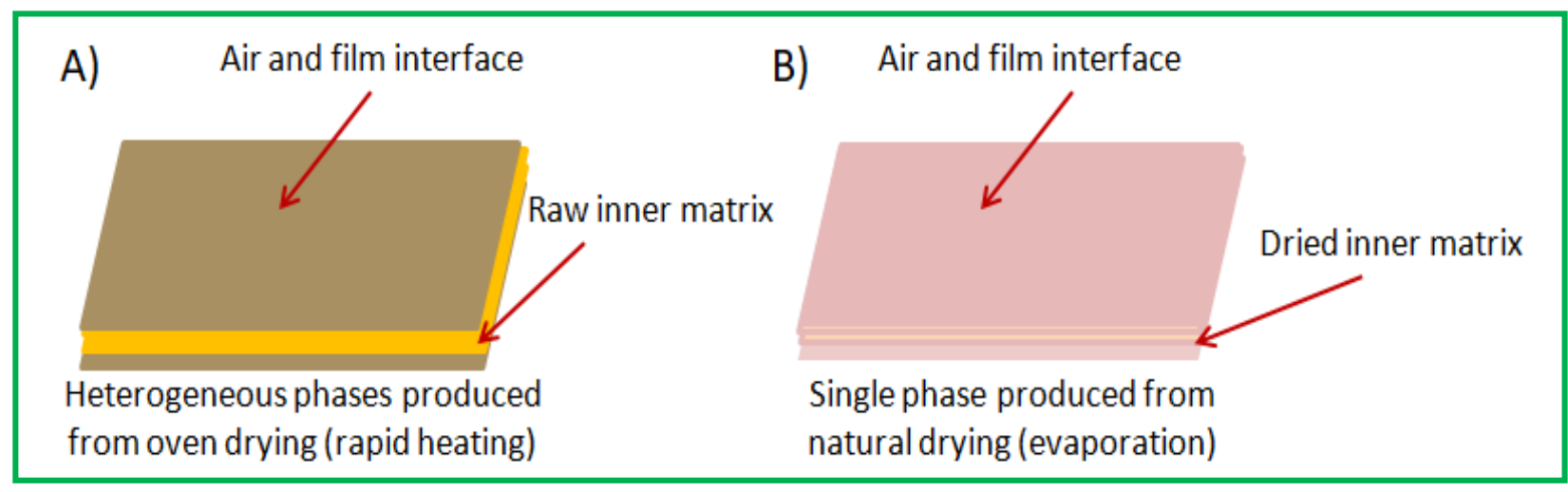

Fig 8: Shows schematically the mechanistic representation of the effect of (A) oven drying, and (B) natural drying on the surface of film.

\section{CONCLUSION:}

Environment friendly bio-nanocomposites films with $250 \mu \mathrm{m}$ thicknesses were successfully fabricated using cellulose nanocrystals synthesized by sulfuric acid hydrolysis of jute fibres as reinforcing phase and potato starch plasticized with glycerol as matrix. A solution $(10 \% \mathrm{w} / \mathrm{v})$ of commercial bleaching powder was effectively used to remove undesirable color of nanocrystals. It is revealed that with the increase of cellulose nanocrystals in the composite film, a gradual and remarkable increase in both tensile strength and Young's modulus was found. Changing of drying techniques from atmospheric to dryer, deteriorate the mechanical property of films due to heterogeneous drying. Naturally atmospheric drying films showed 2.5 to 6 times MPa higher tensile strength than that found from oven dried films. Young's modulus of the films was also increased and found $0.563 \mathrm{GP}$ in presence of $20 \%$ cellulose nanocrystals from naturally drying film. It is concluded that a drastic drying technique would create rapid removal of interlocked solvent and plasticizer after destruction of hydrogen bonds within the matrix. Natural drying technique would certainly provide a self-assembled and entropically stable composites film with higher mechanical properties from other nanoparticles and polymer matrix with UniversePG I www.universepg.com selective solvents. Since fabrication of nanocomposite films with homogeneous dispersion of particles are still challenging, this result will imply a pathway to fabricate desirable film for separation, biomedical and engineering advanced applications.

\section{ACKNOWLEDGEMENTS:}

We gratefully acknowledge the financial support (grant no. reg. admin-3/29473) to the University teachers from the University Grants Commission (UGC) of Bangladesh for conducting this research work in the Department of Applied Chemistry \& Chemical Engineering, University of Dhaka, Dhaka 1000, Bangladesh.

\section{CONFLICT OF INTERESTS:}

The authors declared that there was no conflict of interest.

\section{REFERENCES:}

1. Alexander, J.,Mark, A. Z., Suraj, S. (2013). Thermal, mechanical, and moisture absorption properties of egg white protein bioplastics with natural rubber and glycerol, Prog Biomater. 2(12). https://doi.org/10.1186/2194-0517-2-12 
2. Alves, V.D., Mali, S., Beléia, A., Grossmann, M.V.E. (2007). Effect of glycerol and amylose enrichment on cassava starch film properties. Journal of Food Engineering, 78(3), 941-946. https://doi.org/10.1016/j.jfoodeng.2005.12.007

3. Bader, H.G., Göritz, D. (1994). Investigations on high amylose corn starch films. Part 2: Water vapor sorption. Starch/Stärke,46(7), 249-252. https://doi.org/10.1002/star.19940460704

4. Bertoft E., (2017). Understanding Starch Structure: Recent Progress, Agronomy, 7, 56. https://doi.org/10.3390/agronomy7030056

5. Beytullah, E., and Fatih, K. (2012). Physical Disintegration of Toilet Papers in Wastewater Systems: Experimental Analysis and Mathematical Modeling, Environmental Science and Technology, 46(5):2870-6.

https://doi.org/10.1021/es203589v

6. Biliaderis, C.G., Lazaridou, A., Arvanitoyannis,I. (1999). Glass transition and physical properties of polyol-plasticised pullulan-starch blends at low moisture. Carbohydrate Polymers, 40(1), 29-47.

https://doi.org/10.1016/S0144-8617(99)00026-0

7. Cao, X.D., Chen, Y., Chang, P.R., Stumborg, M., Huneault, M.A. (2008). Green composites reinforced with hemp nanocrystals in plasticized starch. J. Appl.Polym. Sci.109(6), 38043810. https://doi.org/10.1002/app.28418

8. Carla, A. C., Ticiane, S.V, (2019). Cellulose Nanocrystals and Jute Fiber-reinforced Natural Rubber Composites: Cure Characteristics and Mechanical Properties, Materials Research. 22. http://orcid.org/0000-0002-4509-6574

9. Chakraborty, A., Sain, M., Kortschot, M., Cutler, S. (2007). Dispersion of wood microfibers in a matrix of thermoplastic starch and starch-polylactic acid blend. J. Biobased Mater. Bioenergy1(1), 71-77. https://doi.org/10.1166/jbmb.2007.008

10. Daniel, D-L., Juan Carlos, G-Q., Ignacio, MG. Mercedes, G. M., (2019). Influence of Starch Composition and Molecular Weight on Physicochemical Properties of Biodegradable Films, Polymers, 11, 1084. https://doi.org/10.3390/polym11071084
11. Dufresne, A., (2008). Polysaccharide nano crystal reinforced nanocomposites. Can. J. Chem. Rev. Can. Chim. 86(6), 484-494. https://doi.org/10.1139/v07-152

12. Glenn, G.M., Klamczynski, A., Holtman, K.M., Chiou, B.S., Orts, W.J., Wood, D. (2007). Cellulose fiber reinforced starch-based foam composites. J. Biobased Mater. Bioenergy, 1(3), 360-366. https://doi.org/10.1166/jbmb.2007.010

13. John, M.J., and Thomas, S. (2008). Biofibres and biocomposites. Carbohydr. Polym. 71(3), 343-364.

https://doi.org/10.1016/j.carbpol.2007.05.040

14. John, M.J., Anandjiwala, R.D., Pothan, L.A., Thomas, S. (2007). Cellulosic fibre reinforced green composites. Compos. Interface.14(7-9), 733-751.

https://doi.org/10.1163/156855407782106546

15. Kennedy, C.J., Cameron, G.J., Sturcova, A., Apperley, D.C., Altaner, C., Wess, T.J., Jarvis, M.C., (2007). Microfibril diameter in celery collenchyma cellulose: X-ray scattering and NMR evidence. Cellulose,14(3), 235-246. https://doi.org/10.1007/s10570-007-9116-1

16. Krochta, J.M. (2002). Proteins as raw materials for films and coatings: definitions, current status, and opportunities. In Protein-Based Films and Coatings. Ed. A. Gennadios, Boca Raton, FL, USA: CRC Press LCC. https://www.taylorfrancis.com/books/e/9780429 135804/chapters/10.1201/9781420031980-4

17. Kumar, R., Liu, D., Zhang, L. (2008). Advances in proteinous biomaterials. J. Biobased Mater. Bioenergy, 2(1), 1-24. https://doi.org/10.1166/jbmb.2008.204

18. Liu, D., Wu, Q., Chen, H., Chang, P.R. (2009). Transitional properties of starch colloidswith particle size reduction from micro- to nanometer. J. Colloid Interf. Sci. 339(1), 117-124. https://doi.org/10.1016/j.jcis.2009.07.035

19. Pandey, J.K., Kumar, A.P., Misra, M., Mohanty, A.K., Drzal, L.T. Singh, R.P. (2005).Recent advances in biodegradable nanocomposites. J. Nanosci. Nanotechnol. 5(4), 497-52. https://doi.org/10.1166/jnn.2005.111 
20. Reddy, N., Yang, Y.Q. (2006). Properties of high-quality long natural cellulose fibers from rice straw. J. Agric. Food Chem. 54(21), 80778081. https://doi.org/10.1021/jf0617723

21. Reddy, N., Yang, Y.Q., (2007). Natural cellulosefibers from switchgrass with tensile properties similar to cotton and linen. Biotechnol. Bioeng.97(5), 1021-1027. https://doi.org/10.1002/bit.21330

22. Revol, J. F., Godbout, L., Dong, X. M., Gray, D. G, Chanzy, H. Maret, G. (1994). Chiral nematic suspensions of cellulose crystallites; phase separation and magnetic field orientation. Liquid Crystal.16, 127-134. https://doi.org/10.1080/02678299408036525

23. Rhim, J.W. (2007). Potential use of biopolymer-based nanocomposite films in food packaging applications. Food Sci. Biotechnol. 16(5), 691-709. https://doi.org/10.1080/1040839060084636

24. Sakurada, I., Nukushina, Y., Ito, T. (1962). Experimental determination of the elastic modulus of crystalline regions in oriented polymers. J. Polym. Sci.57(165), 651-660. https://doi.org/10.1002/pol.1962.1205716551

25. Tianyu, J., Qingfei, D., Jian, Z., Hongsheng, L.,Long, Y. (2020.) Starch-based biodegradeable materials: Challenges and opportunities, Adv. Ind. Eng.Polym. Res.,3(1), 8-18. https://doi.org/10.1016/j.aiepr.2019.11.003

26. Wei-ming, W., Zai-sheng, C., Jian-yong, Y., Zhao-peng, X. (2009). Changes in Composition,Structure, and Properties of Jute Fibers after Chemical Treatments, Fibers and Polymers, 10(6):776-780. https://doi.org/10.1007/s12221-009-0776-3

27. Yang, K. K., Wang, X. L., Wang, Y. Z. (2007). Progress in nanocomposite of biodegradable polymer. J. Ind. Eng. Chem. 13(4), 485-500.

http://citeseerx.ist.psu.edu/viewdoc/download?d oi=10.1.1.565. 9881\&rep=rep1\&type=pdf

Citation: Rashid MM, Sharif JI, and Ashaduzzaman M. (2020). Drying effect on mechanical properties of bionanocomposite films fabricated from self-assembled cellulose nanocrystals into potato starch. Am. J. Pure Appl. Sci., 2(5), 129-138. https://doi.org/10.34104/ajpab.020.01290138 (c) () 